
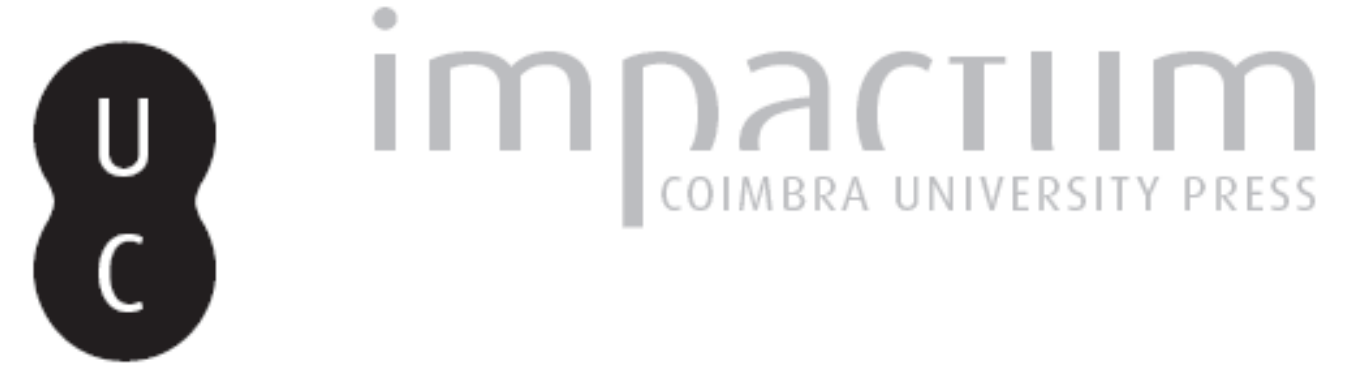

\title{
O interesse científico e a necessidade de conservação da área do Sampaio (Labruge, Vila do Conde)
}
Autor(es):
Araújo, Maria da Assunção
Publicado por: Associação Portuguesa de Riscos, Prevenção e Segurança
URL
persistente:
URI:http://hdl.handle.net/10316.2/40150
DOI:
DOI:https://doi.org/10.14195/1647-7723_4_9
Accessed : $\quad$ 26-Apr-2023 10:33:44

A navegação consulta e descarregamento dos títulos inseridos nas Bibliotecas Digitais UC Digitalis, UC Pombalina e UC Impactum, pressupõem a aceitação plena e sem reservas dos Termos e Condições de Uso destas Bibliotecas Digitais, disponíveis em https://digitalis.uc.pt/pt-pt/termos.

Conforme exposto nos referidos Termos e Condições de Uso, o descarregamento de títulos de acesso restrito requer uma licença válida de autorização devendo o utilizador aceder ao(s) documento(s) a partir de um endereço de IP da instituição detentora da supramencionada licença.

Ao utilizador é apenas permitido o descarregamento para uso pessoal, pelo que o emprego do(s) título(s) descarregado(s) para outro fim, designadamente comercial, carece de autorização do respetivo autor ou editor da obra.

Na medida em que todas as obras da UC Digitalis se encontram protegidas pelo Código do Direito de Autor e Direitos Conexos e demais legislação aplicável, toda a cópia, parcial ou total, deste documento, nos casos em que é legalmente admitida, deverá conter ou fazer-se acompanhar por este aviso.

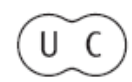




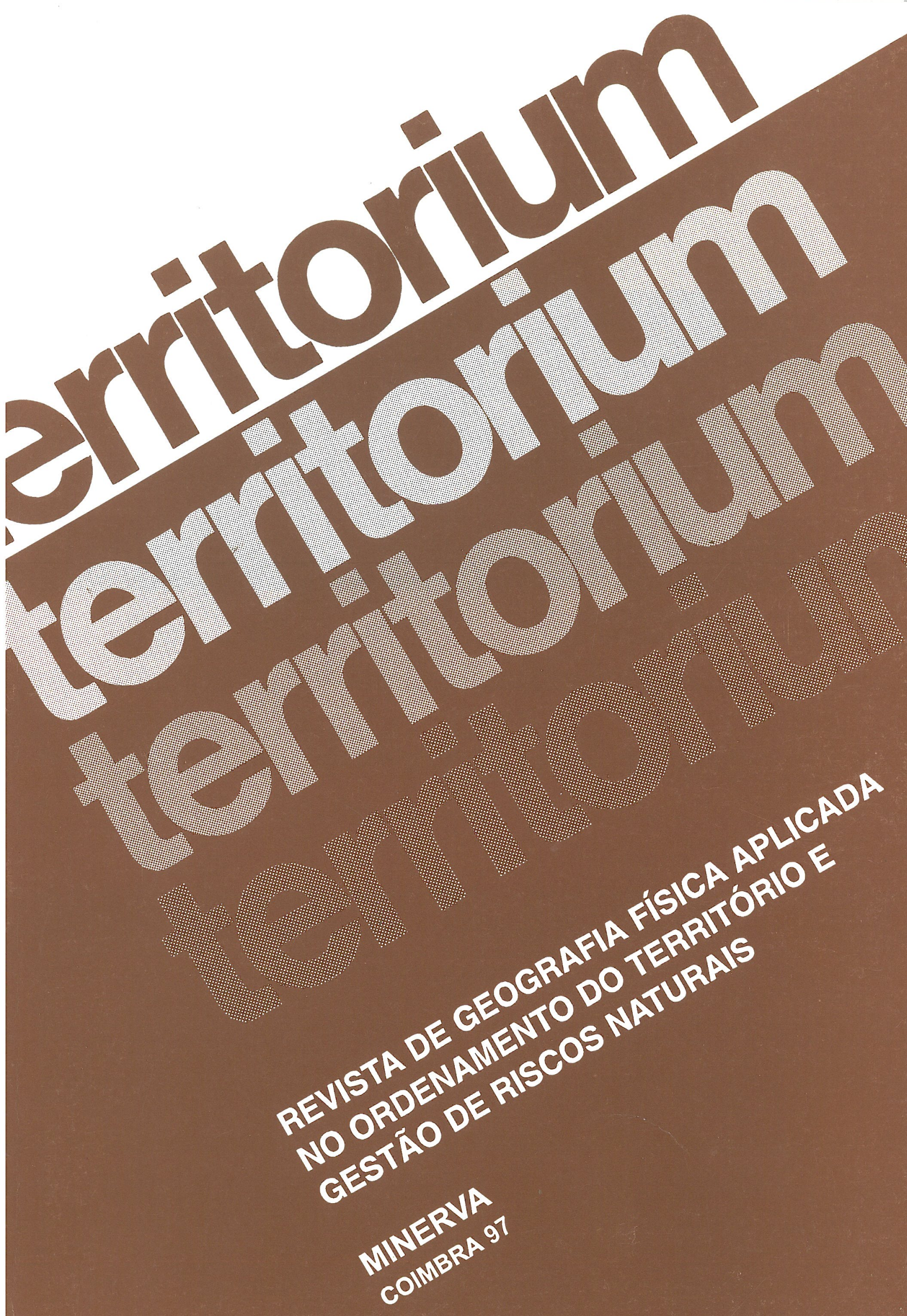




\title{
O interesse científico e a necessidade de conservação da área do Sampaio (Labruge, Vila do Conde)
}

\author{
Maria da Assunçāo Araújo*
}

Resumo

A praia do Sampaio situa-se na freguesia de Labruge, concelho de Vila do Conde, a cerca de $20 \mathrm{~km}$, por estrada, da cidade do Porto. Trata-se de um local onde se encontram aspectos geológicos, geomorfológicos e arqueológicos de grande interesse.

A existência de depósitos marinhos do último interglaciar, situados a altitudes diferentes $(5 \mathrm{e} 9 \mathrm{~m})$ sugere fortemente a influência da neotectónica actuando ao longo das fracturas tardi-hercínicas de direç̧ão NNE-SSW que controlam as linhas gerais da morfologia da área.

Ligado ao depósito marinho de $9 \mathrm{~m}$ de altitude, pode observar-se um belo entalhe basal fóssil (notch, encoche, sapa).

A sequência de depósitos de idade würmiana torna-se bastante rara pelo facto de se encontrar um depósito eólico enquadrado por duas unidades solifluxivas.

A área em questão possui também um castro e diversos outros vestígios de índole arqueológica.

Trata-se duma praia abrigada relativamente aos ventos de norte.

Por tudo isso, e ainda pela sua beleza cénica, trata-se de local bastante frequentado pelos turistas.

Se não houver um grande esforço das autoridades locais no sentido da preservação e da educação ambiental dos utentes da praia, muitos destes vestígios estarão condenados a uma rápida deterioração ou mesmo desaparecimento.

Palavras chave

Entalhe basal, plataforma de erosão marinha, neotectónica, terraço marinho, depósitos solifluxivos, depósitos eólicos, castro, educação ambiental.

\section{Résumé}

La plage de Labruge se trouve à quelques $20 \mathrm{~km}$ de Porto. C'est un lieu avec beaucoup de interêt sur le point de vue géomorphologique et archeólogique.

Il y a un dépôt marin vraisemblablement du dernier interglaciaire à $5 \mathrm{~m}$ et à $9 \mathrm{~m}$ d'altitude. Ça semble une bonne évidence pour l'existence de néotectonique. De plus, les falaises qui entourent ce site semblent toutes taillées au couteau: elles ne sont, très probablement, que des escarpes de faille.

Il y a, aussi, une séquence de dépôts éoliens encadrés par deux unitées solifluxives qui est assez intéressant pour l'étude de l'évolution climatique würmienne.

Ce site a, aussi, quelques aspects archeólogiques intéressants.

C'est une plage proche de la grande ville de Porto. Alors il faut que les autorités prennent conscience de la nécessité de protéger le site de Sampaio e d'éduquer les gens dans le respect du patrimoine naturel et archéologique.

\section{Mots clés}

Encoche basal, plate-forme d'érosion marine, néotectonique, dépôts marins, dépôts solifluxives, dépôts éoliens, "castro", éducation environnementale.

\section{Abstract}

Sampaio's beach, located $20 \mathrm{~km}$ North of Oporto, has many points of interest. There is a fossil wave cut notch and a marine deposit, hanging at 9 meters high. Nearby we can see a deposit of the same age (probably last interglacial), lying at 5 meters. The difference in the altitudes of the two deposits could be explained by a neotectonic effect, as all the cliffs that enclose Sampaio's beach are structurally controlled.

Over the 5 meters marine deposit we find a complex würmian sequence, with two solifluxive deposits and an aeolian deposit between them.

The association of this geomorphological features with a very rare archaeological site makes us emphasise the need of protecting this place.

It is a very demanded beach, so, its protection must be done with the help of the concerned people.

We want to emphasise the need of preservation and protection of this area as a relevant aim for local authorities.

If nothing is done, the consequences of a recently improved accessibility can be rather perverse and the existence of this geomorphological and archeological remains is certainly threatened.

Keywords

Wave cut notch; wave cut platform; neotectonics, marine deposits; solifluxive deposits; aeolian deposits; "castro"; environmental education.

\footnotetext{
* Instituto de Geografia. Faculdade de Letras. Universidade do Porto.
} 


\section{Introdução}

É quase um lugar comum dizer-se que $70 \%$ da população portuguesa vive próximo do litoral. Com efeito, as figuras 1 e 2 mostram, claramente, a importância do processo de litoralização e como ele se tem intensificado nas últimas décadas.

Além do aumento da população residente, têm-se instalado, nos concelhos do litoral, um grande número de actividades económicas que escolhem a proximidade da linha de costa como factor de localização.

O litoral é também particularmente importante para Portugal como recurso turístico, sendo cada vez mais frequentes as infraestruturas dedicadas ao turismo. Entre elas avulta um número muito apreciável de segundas residências que o desafogo económico adquirido por alguma classe média fez multiplicar nos últimos tempos.

Todas estas infraestruturas vão exercendo uma grande pressão sobre a faixa litoral do território. As debilidades de que enferma o ordenamento do território têm permitido que muitas dessas pressões venham a ser particularmente prementes na proximidade da linha de costa, acabando por influenciar directamente

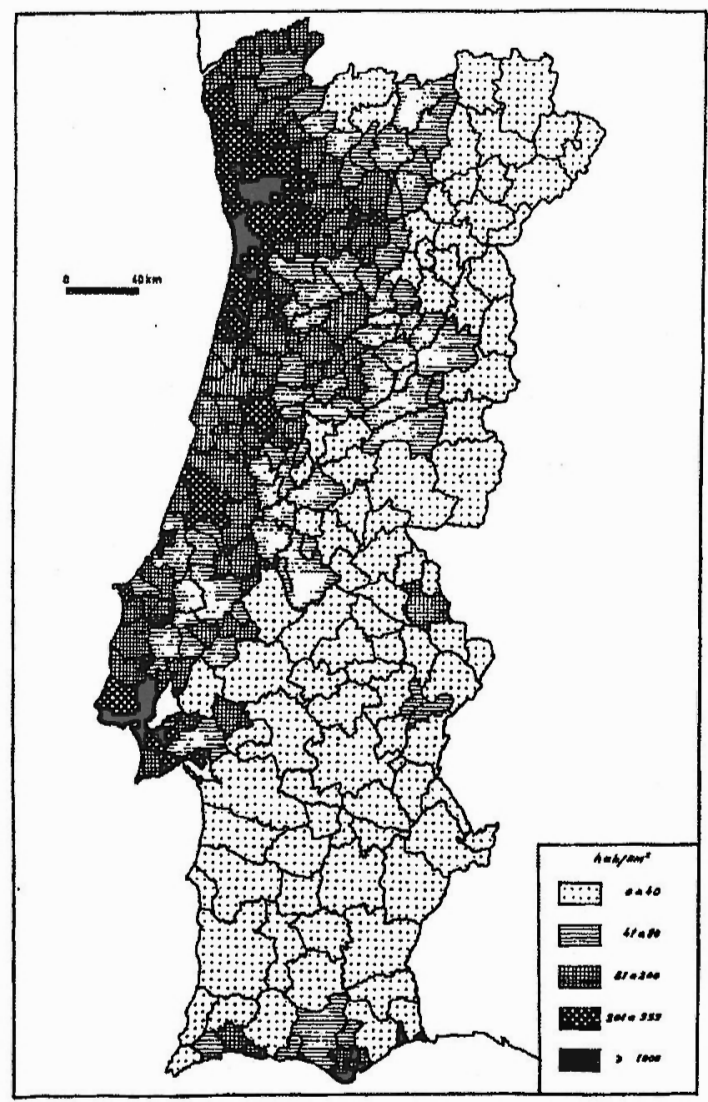

Fig. 1 - Densidade da população em 1970, por concelho. Extraído de J. Gaspar et al., 1979. os ambientes litorais. Basta um rápido percurso pelo litoral dos concelhos de Vila Nova de Gaia e de Matosinhos para nos compenetrarmos da verdade desta afirmação.

Uma vez que os ambientes litorais se situam na interface entre os processos marinhos, continentais e atmosféricos, qualquer modificação verificada em cada um dos elementos da interface pode destruir a sua situação de equilíbrio dinâmico. Esta é a principal causa do seu extremo dinamismo e da complexidade de que o seu estudo se reveste.

É nesse dinamismo que reside a grande fragilidade das áreas litorais. Essa fragilidade ainda se torna mais acentuada devido a fenómenos como a subida do nível do mar, a retenção de areias nas barragens e outras acções antrópicas (destruição das dunas, construção de portos).

Perante isto, a preservação do património natural e construído nas áreas litorais converte-se num problema particularmente agudo, tanto mais importante quanto uma parte do interesse turístico que essas áreas têm depende da conservação dos seus valores naturais e contruídos.

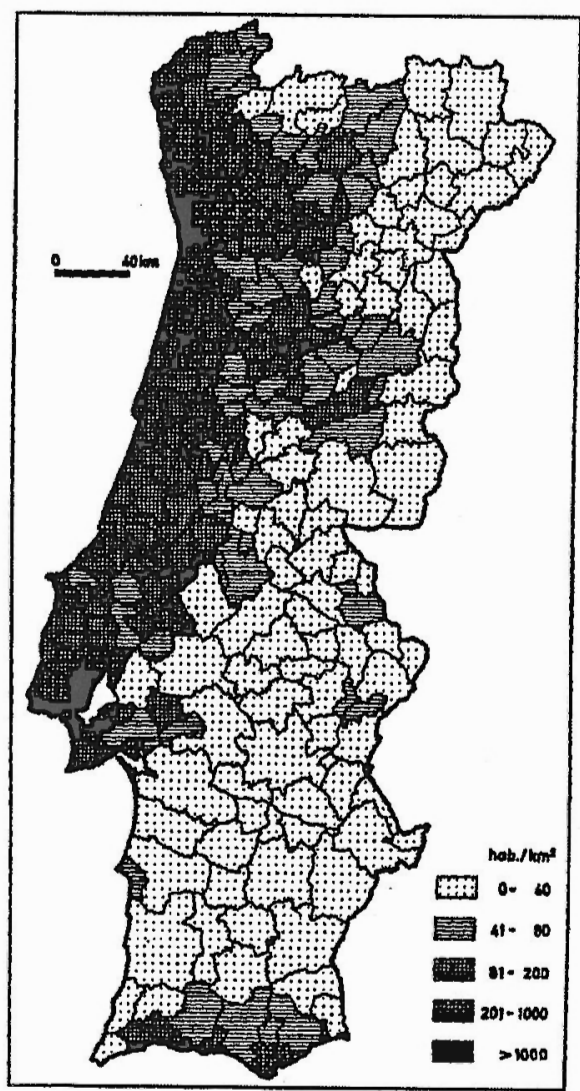

Fig. 2 - Densidade da população em 1981, por concelho. Extraído de C.A. Medeiros, 1994. 
Como conciliar o desejo de um número cada vez maior de pessoas de disfrutar da proximidade do mar com a conservação dos valores ambientais que servem de suporte a essas actividades? Dito de uma forma ainda mais clara: como evitar que o turismo seja uma actividade predadora que destrói aquilo que toca?

Pretendemos discutir este problema recorrendo a um exemplo que conhecemos particularmente bem: o caso do Sampaio em Labruge (Vila do Conde).

\section{Caracterização da área do Sampaio e sua integração no litoral norte de Portugal}

O litoral norte de Portugal coincide com a área em que a linha de costa tem a orientação geral de NNW-SSE e assenta em rochas do Maciço Hespérico. Predominam sectores de costa baixa, constituídos por praias arenosas, mais ou menos extensas, assentes sobre os referidos afloramentos rochosos. Em certos locais, a erosão das praias pode fazer desaparecer a maior parte das respectivas areias, fazendo aflorar, então, as formações graníticas ou metamórficas do Maciço Hespérico. Noutros locais, estas mesmas rochas constituem pontões rochosos onde se desenvolvem pequenas arribas. Trata-se, então, de sectores de costa alta, geralmente de pequena dimensão, delimitando praias arenosas, mais ou menos contínuas e extensas.

As áreas de costa alta, cortando a relativa monotonia dos sectores arenosos predominantes, constituem pontos de interesse paisagístico evidente, que se traduz numa grande apetência por parte do público.

Em certos casos, elas são, também, bastante abrigadas relativamente aos ventos de norte e à ondulação de NW, o que as torna muito atraentes para os veraneantes. É o caso dos rochedos da praia de Miramar (Senhor da Pedra), Lavadores, Boa Nova e Sampaio (Labruge), dentro da área metropolitana do Porto (AMP).

Para norte de Vila do Conde esses afloramentos rareiam e só a norte de Viana do Castelo vamos encontrá-los de novo (caso da Gelfa-Forte do Cão e de Montedor). Só em Montedor temos uma situação comparável à do Sampaio: um pequeno trecho de costa alta, quase deserta eainda relativamente selvagem.

Labruge é uma pequena aldeia com cerca de 2000 habitantes, situada na extremidade sul do concelho de Vila do Conde, no limite com o de Matosinhos. Até meados dos anos oitenta tinha uma feição exclusivamente rural. Junto à praia existiam apenas duas ou três casas.

Um quilómetro a norte da praia de Labruge encontram-se os rochedos do Sampaio.

Tratava-se, até ao fim da década de oitenta, duma área quase completamente virgem, com acesso por uma estrada de terra, estreita e tortuosa.
A poluição visual ainda não estragou este recanto onde o verde dos campos e o azul do mar se casam admiravelmente, numa sugestão da Galiza não muito distante... Ao longe vê-se a aldeia piscatória de Vila Chã.

Na praia do Sampaio encontrámos diversos tipos de depósitos, constituindo uma sequência que ilustra uma boa parte da evolução geomorfológica posterior ao último período interglaciar (cerca de 125.000 anos).

A área do Sampaio corresponde aos dois afloramentos rochosos onde se situam a capela e o castro do Sampaio e o respectivo vértice geodésico, onde se atinge a cota de $23 \mathrm{~m}$ (fig. 3 ). Trata-se do sector mais elevado da linha de costa pertencente à AMP.

Os afloramentos graníticos acima definidos delimitam uma pequena praia, parcialmente abrigada dos ventos de norte e muito concorrida durante o verão.

\section{O património natural da área do Sampaio}

Encontrámos, na área envolvente do Sampaio, um conjunto de formas e depósitos que passamos a analisar.

\section{Afloramento $n^{\circ} I$}

Napraiado Sampaio, a uma cota de $5 \mathrm{~m}$, encontramos uma sequência de depósitos (fig. 4) que compreende, de cima para baixo:

4 - depósito solifluxivo, do tipo "formação areno-pelítica de cobertura";

3 - depósito eólico consolidado, com intercalações de grãos angulosos, devidos, provavelmente, a fenómenos de escorrência muito localizados;

2 - depósito solifluxivo com pedacinhos de carvão;

1 - depósito marinho, provavelmente do último interglaciar (cerca de 125000 anos BP) assente sobre a rocha granítica.

Esta sequência permite definir a existência de duas fases de clima húmido, enquadrando uma outra de clima mais seco (responsável pelo depósito eólico).

Atendendo ao facto de toda a sequência assentar sobre um depósito marinho pertencente ao nível mais baixo (por nós classificado como "nível III" (M. A. ARAÚJO, 1991), esta sequência deverá terse depositado durante a última glaciação.

Foi o único caso em que foi possível encontar um depósito eólico bem conservado intercalado entre duas unidades solifluxivas na área que estudámos, embora essa situação fosse, desde há muito, previsível (M. A. ARAÚJO, 1984), já que certos horizontes, dentro da formação areno-pelítica de cobertura denunciam uma forte contaminação por areias eólicas. 


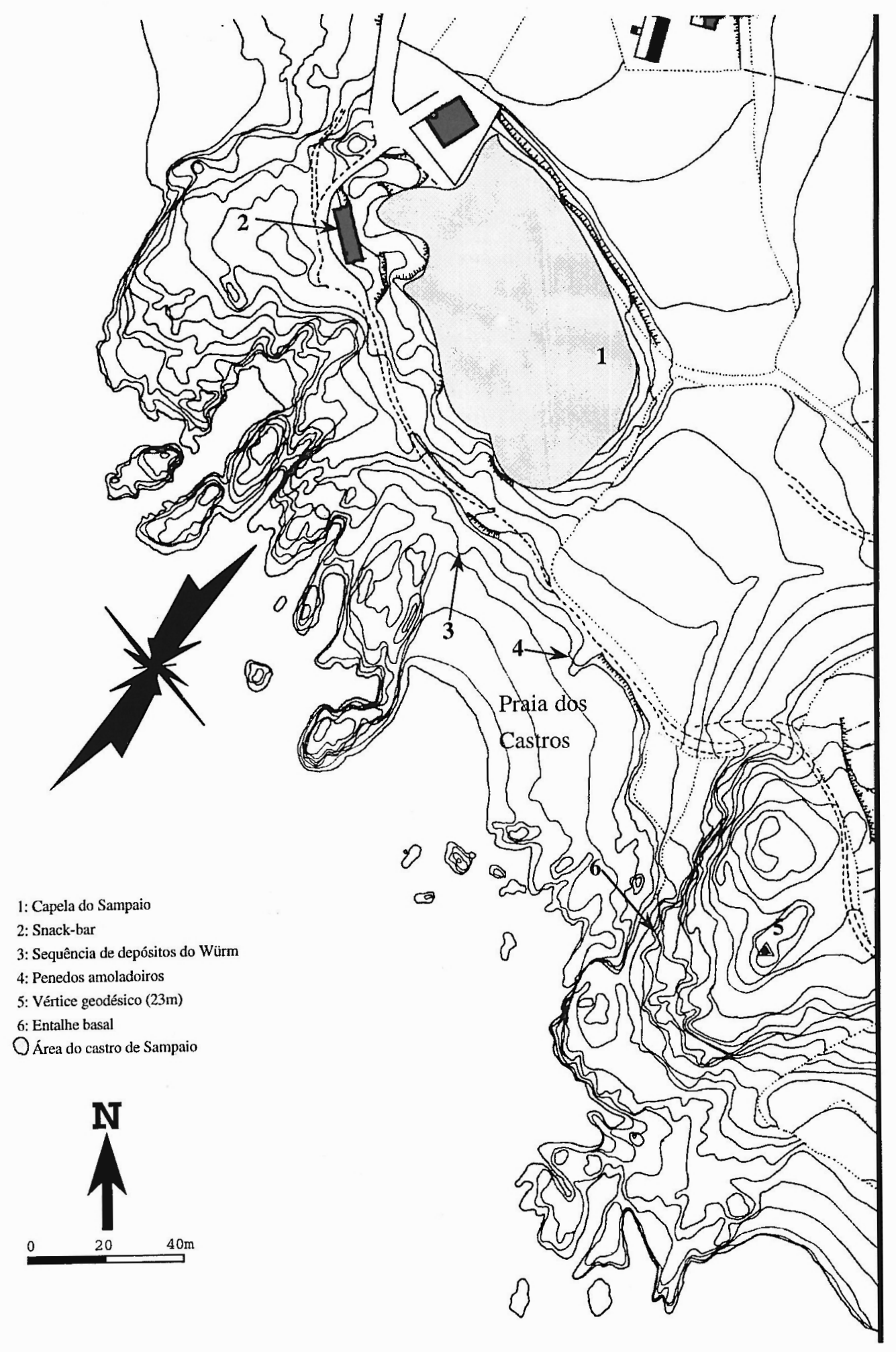

Fig. 3 - A praia do Sampaio. Morfologia e orientação das fracturas 


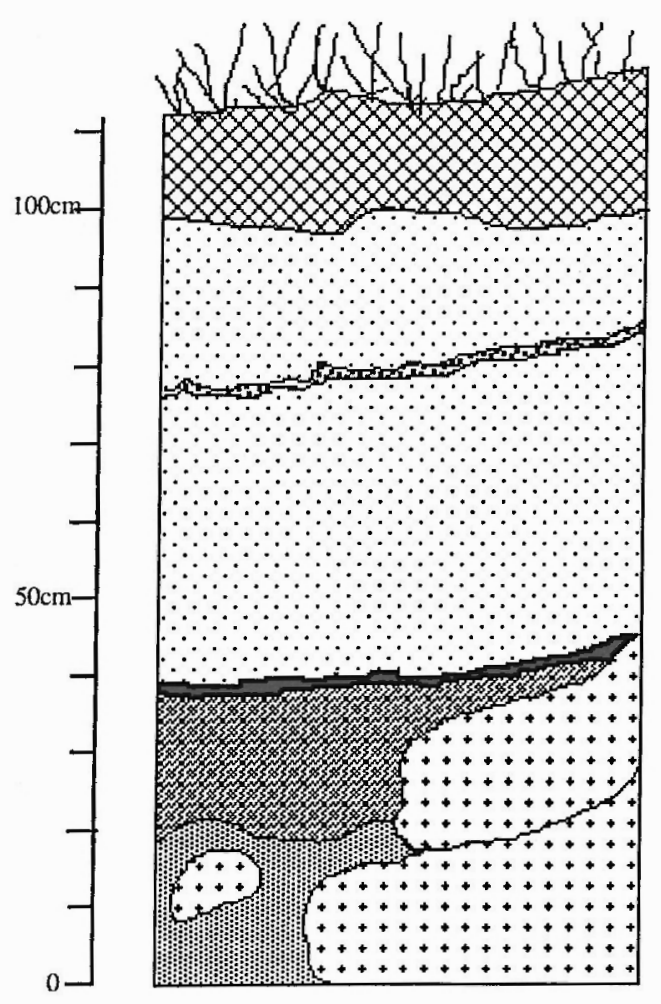

Trata-se, todavia, de um afloramento de reduzidas dimensões, muito exposto ao pisoteio dos utentes da praia, que aproveitam parte do mesmo para descerem até ao mar. Como, na imediata proximidade, existe um caminho onde alguns jovens têm o hábito de praticar moto-cross, é de recear a sua completa destruição, se não se tomarem medidas urgentes de preservação.

\section{Afloramento $n^{\circ} 2$}

Situa-se na face noroeste do rochedo onde está implantado o vértice geodésico do Sampaio, podendo encontrar-se:

1 - uma bela forma fóssil de erosão marinha (=encoche, notch, entalhe basal, fot. 1) que demonstra o trabalho erosivo do mar a um nível de cerca de $9 \mathrm{~m}$;

2 - na sua imediata proximidade situa-se um depósito fóssil de origem marinha.

É o único caso que conhecemos, na nossa área de estudo, em que se pode observar uma forma erosiva fóssil bem desenvolvida e perfeitamente conservada, juntamente com o respectivo depósito correlativo.

Se assumirmos que os depósitos marinhos encontrados nestes dois locais são correlativos de uma mesma fase no estacionamento do nível do mar, a existência de dois depósitos marinhos idênticos, a altitudes de 5 e $9 \mathrm{~m}$, permite inferir a existência de
Fig. 4 - Sequência estratigráfica do corte de Sampaio, Labruge (Vila do Conde). Altitude da base: $5 \mathrm{~m}$.

Nv superior da formação
de cobertura
Leito c/ elementos
angulosos
Arenito
é́lico
Crosta
ferruginosa
Formação de cobertura
(nv inferior)

Nv superior da formação

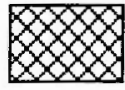
.

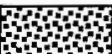

(granito) movimentos tectónicos muito recentes que teriam soerguido o sector do vértice geodésico relativamente àquele onde se implantou a capela do Sampaio.

Na figura 3 representámos, além da topografia de pormenor da área, um diagrama onde registamos a orientaçãoe dimensão acumulada das fracturas expostas nas rochas da área do Sampaio. Foram representadas as direcções de 160 fracturas. Há uma evidente concentração dessas fracturas segundo a orientação NNE-SSW. Ora, é justamente essa a orientação das vertentes rectilíneas que limitam os afloramentos rochosos representados no mapa da figura 3.

Assim, se admitirmos que o desnível entre os dois afloramentos de depósitos marinhos tem origem tectónica, parece-nos provável que a respectiva movimentação se tenha efectuado ao longo das fracturas com a orientação NNE-SSW, que limitam o relevo onde se situa o vértice do Sampaio.

Tratar-se-ia de uma reactivação das fracturas tardi-hercínicas relacionada com o desenvolvimento de uma tensão de direç̧ão WNW-ESE na margem ocidental ibérica (A. RIBEIRO, 1984).

O caso particular do Sampaio, em que um local de costa alta aparece associado a um depósito marinho aparentemente soerguido parece comprovar uma ideia mais geral: a de que os locais de costa alta são, no contexto que estudámos, locais onde existe uma tendência tectónica positiva e em que os depósitos 
Fot. 1 - Entalhe basal fóssil (=sapa, encoche, notch), existente na face virada a norte do morro do vértice geodésico do Sampaio. Altitude $=9 \mathrm{~m}$.

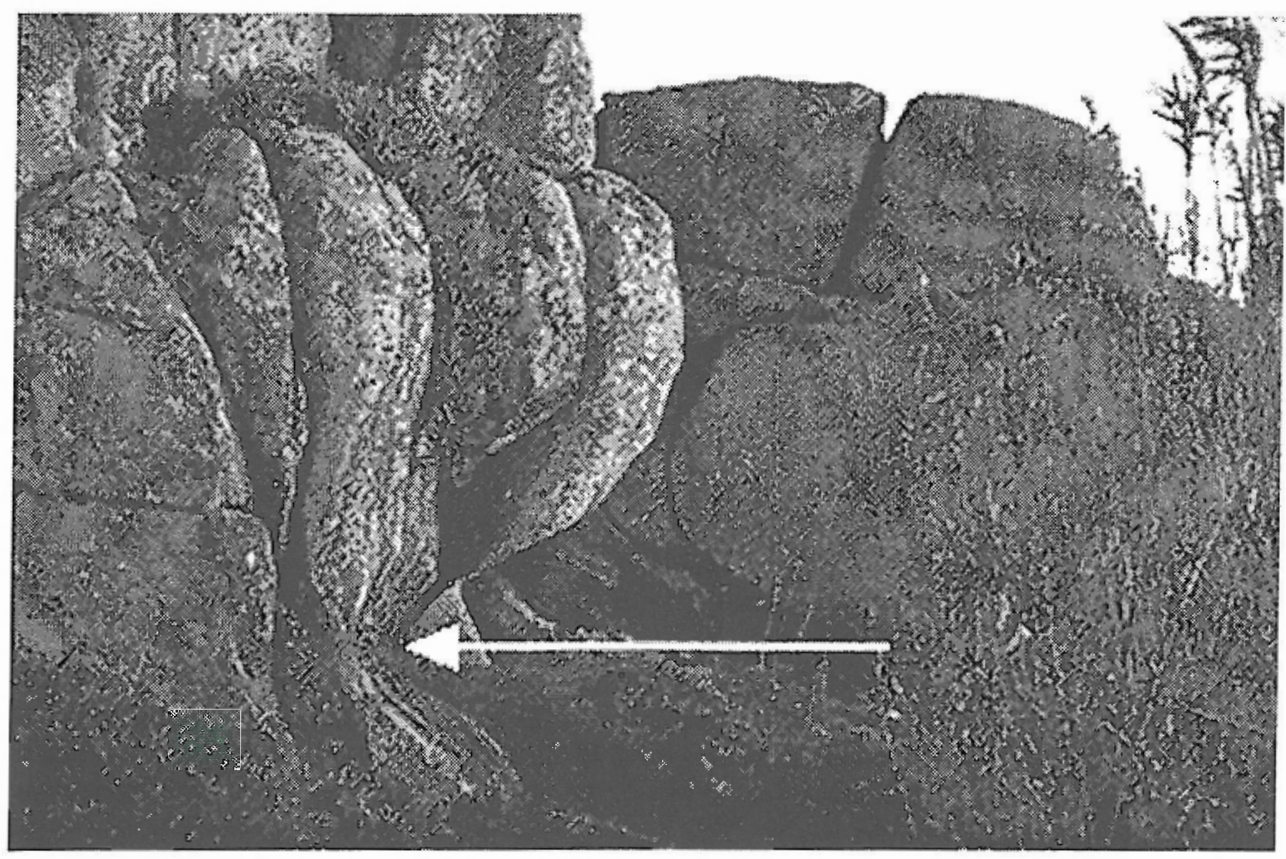

marinhos do último interglaciar aparecem mais altos do que nas áreas contíguas.

A figura 5 , que mostra a altitude máxima dos afloramentos dos depósitos marinhos do último interglaciar, e a figura 6 , que mostra a altitude máxima dos afloramentos rochosos situados na imediata proximidade da linha de costa, parecem apontar nesse mesmo sentido.

É de referir, também, o papel de santuários da vida animal e vegetal que esses troços de costa "selvagem" constituem.

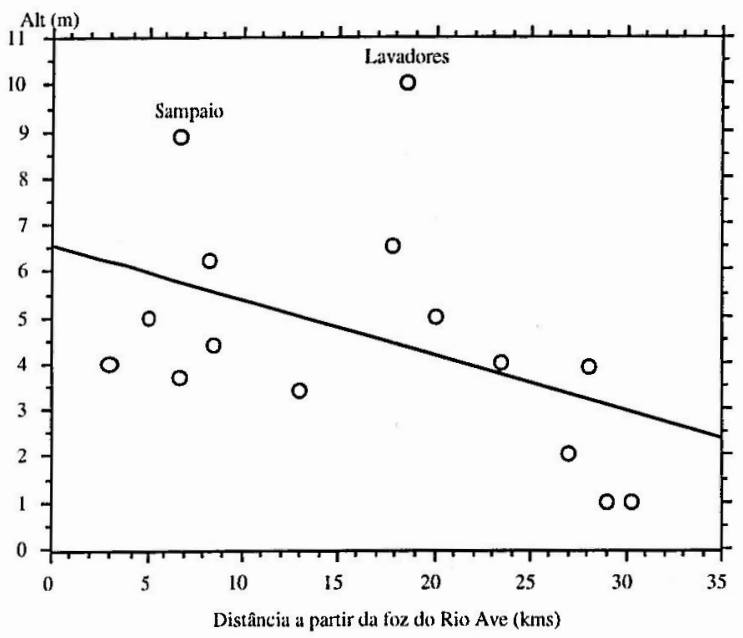

Fig. 5 - A altitude máxima dos afloramentos dos depósitos do último interglaciar entre a foz do rio Ave e a latitude de Espinho e a respectiva recta de regressão.
Conhecemos bem (L. VICENTE, 1993) o importante papel que os litorais rochosos têm na reprodução e sustentação das espécies marinhas juvenis. Entre a praia de Angeiras e a ponta da Gafa (Mindelo) existem afloramentos rochosos que emergem durante a maré baixa, ou ficam submersos a pequenas profundidades, que constituem uma "nursery"quase contínua, de mais de $5 \mathrm{~km}$ de extensão, cujo centro geométrico é, justamente, o pequeno pontão do Sampaio.

Torna-se evidente que um excesso de actividades humanas poderá comprometer seriamente a base em que repousa a actividade piscatória de povoações como Angeiras e Vila Chã.

Ocontactoentreas rochas graníticas emetamórficas, bem visível na praia de Labruge, também tem um claro interesse geológico. Com efeito, junto desse contacto, podem encontrar-se rochas negras, do tipo dos anfibolitos, em que a erosão diferencial desenvolveu formas caprichosas (Penedo das Cobras e da Patada do Cavalo situados na Pedra Negra: cerca de $300 \mathrm{~m}$ a sul do vértice geodésico de Sampaio. Ver figura 7).

\section{O património arqueológico da área do Sampaio}

Era conhecida, desde os estudos do $\mathrm{Arq}^{\circ}$ Fernando Lanhas (1969), a existência de um castro no morro do Sampaio.

Desde há cerca de 4 anos, a preservação e o estudo deste castro foram definidos como objectivos prioritários pelo serviço de Arqueologia da Câmara Municipal de Vila do Conde. Desde então têm sido realizadas escavações, todos os anos, por altura do 


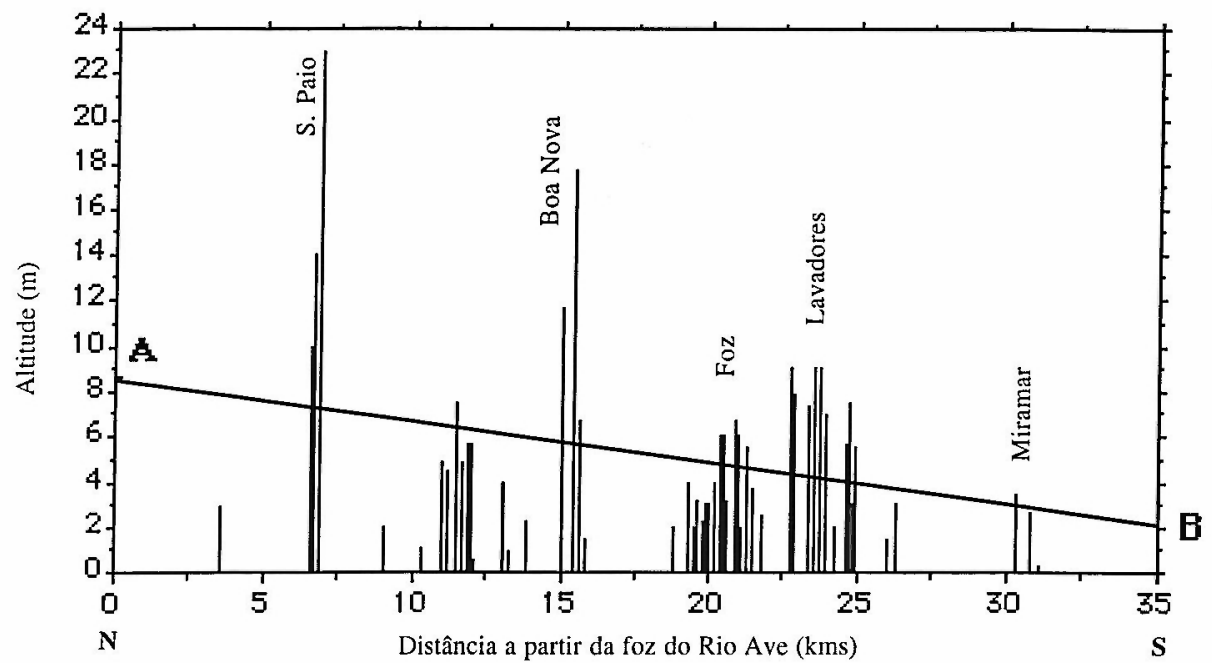

Fig. 6 - A altitude dos afloramentos de bed-rock situados na imediata proximidade da linha de costa, entre a foz do Rio Ave e Espinho e a respectiva regra de regressão $(A-B)$.

verão, recorrendo aos estudantes inscritos em campos de trabalho internacionais.

Trata-se de um castro cuja principal importância reside no seu carácter atípico, já que é o único de que se tem conhecimento em Portugal, situado praticamente sobre a linha de costa.

Para além do castro, existem outros motivos de interesse arqueológico na área do Sampaio.

Assim, na pequena praia de bolso situada entre os dois principais afloramentos rochosos da área, significativamente designada como "Praia dos Castros", encontram-se "penedos amoladoiros" (F. LANHAS, 1969). Trata-se de pequenas depressões alongadas, escavadas na rocha granítica, que teriam servido para as populações neolíticas polirem os utensílios líticos que utilizavam.

O caminho empedrado que liga os dois afloramentos rochosos, onde, infelizmente, muitos jovens se dedicam à prática do motocross, é designado como "Estrada Velha" e corresponderia ao resto duma estrada romana.

Para além das peças de cerâmica e restos de mós que foram encontrados no castro de Sampaio, a área é fértil em achados de tipo paleolítico, de que o trabalho de F. LANHAS (1969) representa vários exemplares.

\section{Conclusão: Algumas sugestões para preservação do património do Sampaio}

A melhoria dos acessos à área do Sampaio, levada a cabo no ano de 1993, conduziu, inevitavelmente a um excesso de ocupação, sobretudo durante os fins de semana. O aumento da ocupação conduz, necessariamente, a uma certa deterioração do ambiente que se traduz:

- no estacionamento desordenado, prejudicando as próprias escavações e destruindo os depósitos,

- na utilização dos caminhos que conduzem ao castro e ao vértice geodésico como pistas de motocross,

- no vazamento de lixos da construção civil e dos veraneantes.

As repetidas agressões ambientais poderão conduzir a uma degradação irreversível do património paisagístico, arqueológico e geológico.
Fig. 7 - Aspectos arqueológicos na área do Sampaio (Labruge, Vila do Conde). Adaptado de F. LANHAS, 1969.

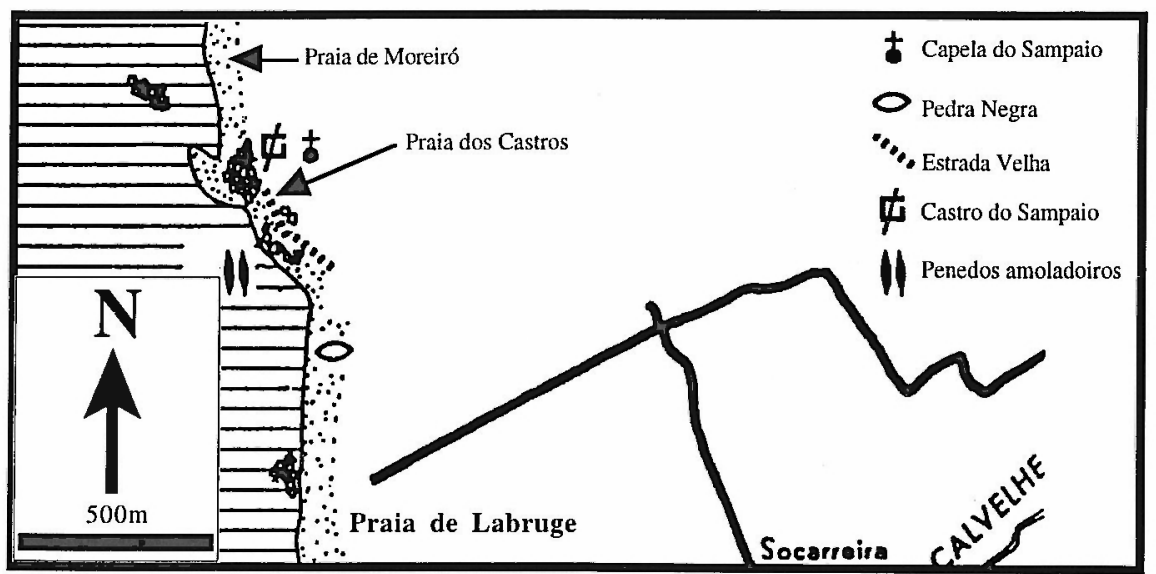


Além disso, o PDM de Vila do Conde prevê uma ocupação bastante densa da área de Labruge. Deste modo, é muito provável que, quando os apartamentos previstos estiverem concluídos, saturada a praia de Labruge, onde se tem assistido a um apreciável deficit de areias, os veraneantes partirão, inevitavelmente, à procura de novos locais. Ora, o local mais próximo da praia de Labruge, é, justamente, o Sampaio.

A acreditar na necessidade de preservar um terço do litoral no seu estado selvagem (François Ramade, Univ. Paris-Sud, comunicação oral em Outubro de 1994), podemos perguntar-nos:

- que fazer para impedir que esta pequena jóia, este lugar mágico, seja descaracterizado, sabendo que se situa tão próximo $(20 \mathrm{~km})$ duma cidade como o Porto?

- como evitar a destruição do seu rico património arqueológico e geomorfológico?

A implementação dos POOCs (Planos de Ordenamento da Orla Costeira) poderá permitir a salvaguarda de alguns dos valores a proteger. Porém, também poderá conduzir a uma certa artificialização desta área, cuja principal beleza se traduz no seu aspecto selvagem.

Independentemente das obras necessárias para realizar a valorização do Sampaio, é importante sublinhar que a educação das pessoas e o desenvolvimento de um saudável orgulho no património natural e construído de cada região, pode ser o mais eficaz processo de proteç̧ão desse mesmo património.

Assim, uma campanha de esclarecimento dos visitantes (com cartazes e folhetos policopiados) e de educação ambiental nas escolas da região, permitiria, a baixos custos, um processo de consciencialização da população, sobretudo da população em idade escolar, mais receptiva à importância da conservação ambiental.

A natural atracção da população pela beleza cénica da área do Sampaio, bem com o facto dela conter muitos e variados motivos de interesse, apontam para a necessidade de explorar as diversas vertentes científicas desta área e de utilizá-la com um local de sensibilização da população em geral e dos jovens, em particular, para esses ramos de conhecimento.

Por isso, parece-nos que se deveria organizar um centro de informação, onde fosse disponibilizada a informação impressa existente, bem como sessões de diapositivos e vídeos sobre os aspectos paisagísticos, arqueológicos, geológicos e geomorfológicos da área.

Contudo, neste como em outros domínios, não bastainformar e consciencializar as pessoas.É preciso, também que as entidades públicas (locais e nacionais) façam a sua parte.

Assim, não basta proibir o estacionamento de veículos em certos locais: é preciso criar alternativas de estacionamento. Eé preciso que existam regras bem definidas e que elas sejam suficientemente publicitadas. Mas depois delas criadas há que agir com coragem política de molde a que as regras sejam respeitadas.

Esse aspecto aplica-se particularmente bem a dois dos maiores problemas deste litoral: o vazamento de lixos (nomeadamente da construção civil) e a condução em âreas do domínio público marinho (praias, dunas e arribas).

\section{BIBLIOGRAFIA}

ARAÚJO, M. Assunção (1984) - "A formação "areno-pelítica de cobertura"- alguns resultados dum estudo preliminar"-Biblos, Vol. LX, Coimbra, Fac. Letras, p. 71-89.

ARAƯJO, M. Assunção (1991) - Evolução geomorfológica da plataforma litoral da região do Porto. Porto, ed. da autora, FLUP, 534 p., 1 anexo e 3 mapas fora do texto.

ARAÚJO, M. Assunção (1994) - "Protection and Conservation of Sampaio Area (Labruge, Vila do Conde, North of Portugal)", Littoral/94 proceedings, Associação Eurocoast-Portugal, IHRH (Instituto de Hidráulica e Recursos Hídricos da Univ. do Porto) e ICN (Instituto de Conservação da Natureza), Vol. II, p. 865-877.

GASPAR, J, et. al. (1979) - Portugal em mapas e nümeros, Col. Espaço e sociedade, Livros Horizonte, Lisboa, 1988 p.

LANHAS,F., BRANDÃO, D. Pinho (1969) - “Inventário de objectos e lugares com interesse arqueológico", Revista de Etnografia, Museu Etnog. e Hist, Vol, XII, T. 2, p. 295-342.

MEDEIROS, C. A. (1994) - Geografia de Portugal. Ambiente natural e ocupação humana: uma introdução. Col. Imprensa Universitária, ${ }^{\circ} 58$, Ed., Estampa, Lisboa, 250 p.

RIBEIRO, A. (1984) - "Néotectonique du Portugal", Livro de Homenagem a Orlando Ribeiro, Centro de Estudos Geográficos, Lisboa, p. 173-182.

VICENTE, L. (1993) - "Áreas protegidas e conservação da natureza na orla costeira portuguesa". Resumos das Comunicações do Seminário sobre a zona costeira de Portugal, ambiente, gestão e conservação, organizado pela Associação EUROCOAST-PORTUGAL, no IST, Lisboa. 